\title{
Thrombin use in surgery: an evidence-based review of its clinical use
}

Sung W Ham'

Wesley K Lew'

Fred A Weaver ${ }^{2}$

'University of Southern California, Department of Surgery, Los Angeles, CA, ${ }^{2}$ Cardiovascular Thoracic Institute at the University of Southern California, Los Angeles, USA
Correspondence: Fred A Weaver I520 San Pablo Street, Suite 4300, Los Angeles, CA 90033, USA

Tel +l 3234425988

$\mathrm{Fax}+\mathrm{I} 323$ 442-5735

Email fweaver@surgery.usc.edu
This article was published in the following Dove Press journal:

Journal of Blood Medicine

21 July 2010

Number of times this article has been viewed

Abstract: When surgical ligation of bleeding fails, or is not possible, surgeons rely on a number of hemostatic aids, including thrombin. This review discusses the history, pharmacology and clinical application of thrombin as a surgical hemostat. The initial thrombin was bovine in origin, but its use has been complicated by the formation of antibodies that cross-react with human coagulation factors. This has been associated with life-threatening bleeding and in some circumstances anaphylaxis and death. Human thrombin, isolated from pooled plasma of donors, was developed in an effort to minimize these risks, but its downsides are its limited availability and the potential for transmitting blood-borne pathogens. Recently a recombinant thrombin has been developed, and approved for use by the FDA. It has the advantage of being minimally antigenic and devoid of the risk of viral transmission. Thrombin is often used in conjunction with other hemostatic aids, including absorbable agents such as Gelfoam, and with fibrinogen in fibrin glues. The last part of this review will discuss these agents in detail, and review their clinical applications.

Keywords: bovine, recombinant, human, thrombin, antigenicity, antibodies, food drug administration (FDA)

\section{Introduction}

In any surgical procedure, hemostasis is vital to success. When surgical ligation of bleeding vessels or electrocautery of smaller vessels fails, or is not possible, surgeons rely on a number of hemostatic aids: one such hemostatic ancillary is thrombin.

Thrombin has a long history as a vehicle to affect hemostasis. Descriptions can be found in the European literature as early as 1892 for the use of thrombin. ${ }^{1}$ Early on, thrombin was used by barbers and boxers, for hemostasis of shaving cuts and fight lacerations. Thrombin has been purified from numerous sources and used as a clinical aid for topical hemostasis for more than 60 years. Records citing thrombin use in surgery date back to the 1940s. Since then its use has grown exponentially, and now thrombin is used in more than 1 million patients in the United States each year at a cost of 250 million dollars. ${ }^{2}$ Over the past few years, there have been new developments in thrombin, namely human thrombin, and FDA approval of recombinant thrombin. ${ }^{3,4}$

This review will discuss the mechanism by which thrombin acts, the history of bovine thrombin, the development of human thrombin, methods of thrombin delivery in clinical applications, and finally the future of thrombin in regards to recombinant technologies. 


\section{Mechanism of thrombin}

Thrombin has a number of well-studied biological activities, which serve to achieve coagulation and hemostasis. With tissue injury and bleeding, exposed collagen and released tissue factor cause activation of the intrinsic and extrinsic coagulation pathways. Both pathways lead to activation of factor $\mathrm{X}$ which along with activated factor $\mathrm{V}$ forms a complex that cleaves the prothrombin protein into the active thrombin molecule. Thrombin production is the final coagulation step required to cleave fibrinogen into fibrin which provides a hemostatic lattice for platelet aggregation and thrombus formation at the site of injury (Figure 1).

In addition to the coagulation cascade, thrombin can act directly on a number of cell types. At the smooth muscle cell, it causes vasoconstriction which aids in hemostasis. By activating platelets it promotes their aggregation at the site of thrombus. Activated thrombin also acts as a mitogen and chemoattractant for neutrophils and fibroblasts, and even induces the formation of vascular endothelial growth factor (VEGF) for tissue and vascular remodeling and repair. ${ }^{1,2,5}$

Interestingly, thrombin not only promotes coagulation, but can also activate the anticoagulant system through protein $\mathrm{C}$. When there is vascular injury the procoagulant effects of thrombin are activated as described above. However, when there is no vascular disruption, thrombin will interact with thrombomodulin to activate protein $\mathrm{C}$ to improve circulation through an anticoagulant effect. ${ }^{6}$

Through all of these varied actions, thrombin promotes and modulates coagulation. For the purpose of this treatise we will confine the discussion to its prothrombotic role and how that has been harnessed to limit bleeding in a variety of surgical procedures.

\section{Bovine thrombin}

The initial source of thrombin was from a bovine origin and its effectiveness at facilitating surgical hemostasis resulted in it quickly becoming a popular surgical ancillary. With increased usage and thus patient exposure, isolated case reports surfaced suggesting that bovine thrombin may be operational in surgically-related bleeding abnormalities. The first report in the literature questioning bovine thrombin safety was in 1989 by Flaherty et al. ${ }^{7}$ They identified four patients with prior bovine thrombin exposure and unexplained prolonged thrombin times (greater than 300 seconds).

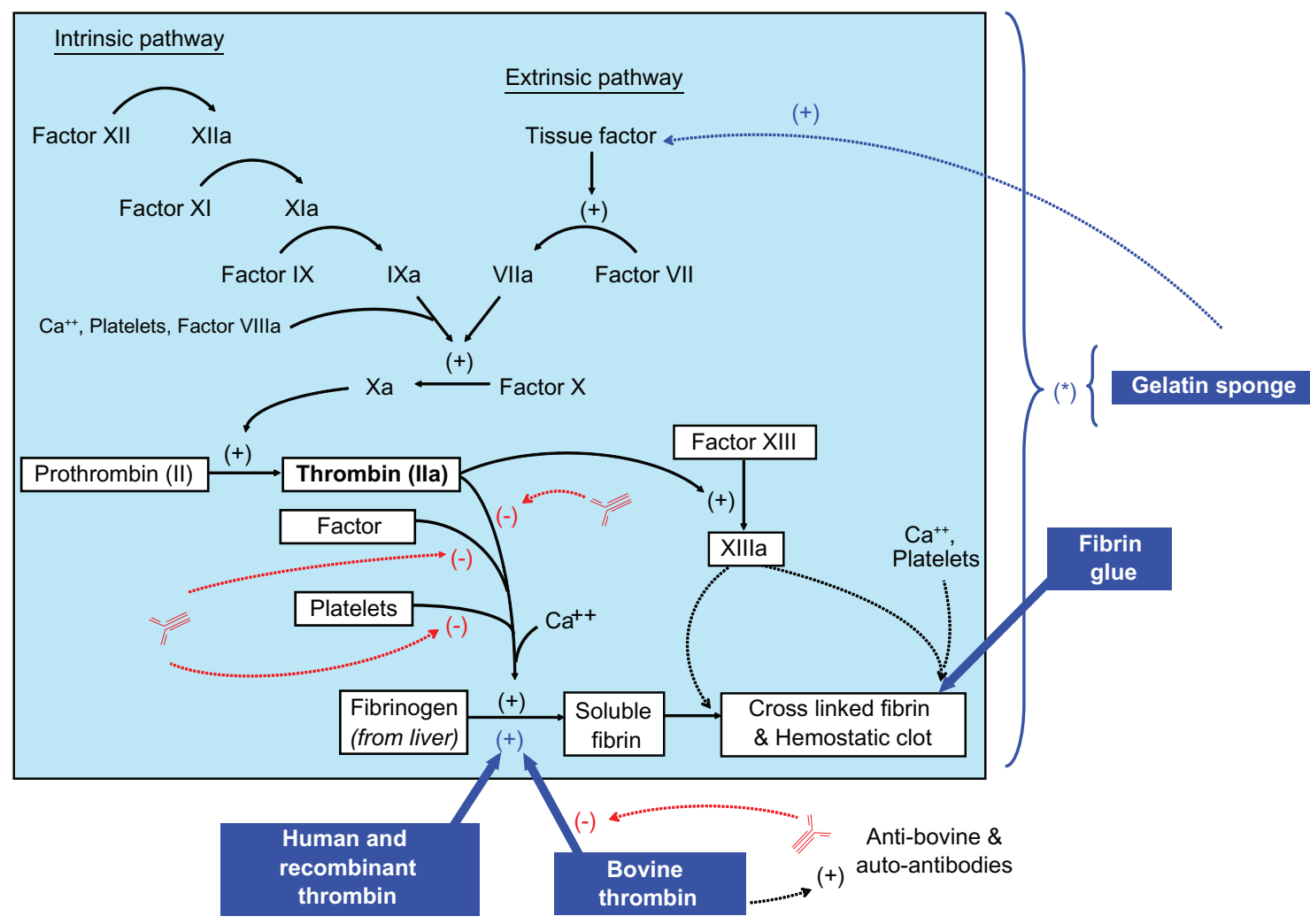

Figure I Diagram of coagulation cascade. Blue boxes and arrows include various hemostatic agents with their mechanism of actions. (*) these agents affect the entire coagulation cascade by concentration and by creating a matrix for coagulation factors at the bleeding site. Red arrows indicate the inhibition caused by bovine generated antibodies to thrombin, factor $\mathrm{V}$, and platelet antiphospholipids. 
Mixing studies suggested the presence of an inhibitor, and the thrombin test times were able to be corrected if human thrombin was substituted for bovine thrombin in the test reagents. The antibodies to bovine thrombin were isolated from the patients, and found to prolong the thrombin times if added to the plasma of normal patients.

The actual antibody generated by bovine thrombin exposure was further characterized by Zehnder in $1990 .{ }^{8}$ He reported a 65-year-old patient who underwent a cardiac procedure complicated by uncontrolled and persistent postoperative bleeding. The patient's factor $\mathrm{V}$ activity was $1 \%$ of normal and was not corrected by mixing with normal plasma, demonstrating the presence of an inhibitor against factor $\mathrm{V}$. This inhibitor was found to be an antibody of bovine factor $\mathrm{V}$ that cross-reacted with the patient's own factor $V$ (Figure 1). The source of the bovine factor $V$ was from the bovine thrombin preparation which contained not only thrombin, but other bovine plasma proteins. Similar case reports soon surfaced documenting coagulopathy that was associated with bovine thrombin exposure. Additional bovine thrombin antibodies have been isolated, including antibodies to the bovine thrombin itself. ${ }^{9,10}$

In 1994, Ortel reported a case series of four patients with acquired factor $\mathrm{V}$ inhibitors from presumed repeated exposure to bovine thrombin preparations. The authors reviewed the literature and identified an additional thirteen patients with documented bovine thrombin preparation induced factor $\mathrm{V}$ antibodies. They noted that even though all seventeen patients had the factor $\mathrm{V}$ inhibitor, each patient had a different clinical course ranging from asymptomatic to life threatening hemorrhage. ${ }^{11}$ Despite the accumulating data concerning factor $\mathrm{V}$ antibody generation, the commercial use of bovine thrombin continued and in fact increased. However by 1996 the weight of the evidence resulted in the FDA attaching a Black Box drug warning label to all bovine thrombin containing products. ${ }^{2}$

In addition to hemorrhage, case reports of thrombotic reactions to antibodies generated by bovine thrombin preparations began to surface. In a study with eighty-eight hemodialysis patients ${ }^{12}$ and another case report with one cardiac patient ${ }^{13}$ the authors demonstrated certain patients exposed to bovine thrombin preparations developed antiphospholipid antibodies causing subsequent thrombosis. More bovine thrombin induced antibodies continued to be discovered, as mice experiments by Schoenecker et al in 2001 demonstrated autoantibodies similar to those found in autoimmune disorders like systemic lupus erythematosus ( SLE) could be caused by bovine thrombin exposure. ${ }^{14}$
To better delineate the incidence of antibody formation following bovine thrombin exposure, Ortel in 2001 prospectively studied 151 patients undergoing cardiac surgery. The authors found more than $95 \%$ of patients developed a seropositive response to bovine coagulation proteins, and 51\% manifested elevated antibody levels to the corresponding human coagulation proteins after bovine thrombin exposure. Furthermore, 15 of these 151 patients had had previous surgeries and were positive for preoperative antibodies to bovine proteins from assumed previous thrombin exposure. These 15 had significantly more adverse effects $(73.3 \%)$ when compared to those without previous surgery or antibodies $(33.8 \%, P-0.0042) .{ }^{15}$

In 2002, another review by Streiff documented one hundred and twenty-six cases of factor $\mathrm{V}$ inhibitors found in the medical literature. These cases included patients with spontaneous and bovine thrombin induced factor $\mathrm{V}$ inhibitors. Interestingly a majority of the cases had been found in the previous ten years indicating an increasing incidence. Fiftyeight of the patients were bovine thrombin induced only, and $33 \%$ developed some sort of bleeding complication. ${ }^{16}$

Almost every surgical specialty has had a case study or series of adverse events related to the use of bovine thrombin: neurosurgery, ${ }^{17-19}$ pediatric surgery, ${ }^{20-23}$ cardiac surgery, ${ }^{18,24,25}$ ob-gyn, ${ }^{26}$ vascular, ${ }^{27,28}$ and nephrology. ${ }^{29}$ Despite this evidence bovine thrombin continued to be widely used, with reported market growth to $\$ 247$ million in $2007 .{ }^{30}$ The major reason for the continued popularity of bovine thrombin was the lack of an alternative thrombin preparation. However, human thrombin and more recently a recombinant thrombin are now available, with new evidence showing a safer profile and less immunogenic reactivity with recombinant thrombin in particular. These products show promise in the surgical ancillary market.

\section{Human thrombin}

The adverse immunological effects associated with bovine thrombin have lead to the development of thrombin from alternative sources. Human derived thrombin is one such alternative. Human thrombin is isolated from pooled human plasma donors at United States (US) licensed collection centers. All donors are tested for blood-borne diseases (HIV, hepatitis, parvovirus B19). The plasma is then processed through a series of separation and filtration steps followed by incubation of the solution with calcium chloride to isolate and activate prothrombin to thrombin. The solution subsequently undergoes ultrafiltration, vapor heat treatment, solventdetergent treatment, sterile filtration and freeze-drying. 
The vapor heat and solvent-detergent treatment steps used in the manufacturing process have been shown to be capable of significant viral reduction. No procedure, however, has been shown to be completely effective in removing viral infectivity from derivatives of human plasma. Therefore although relatively safe, there is still no assurance that human thrombin is completely free of blood-borne pathogens. ${ }^{31-34}$ An additional issue is the finite availability of human-derived blood products and whether the supply can be sufficient for the potential demand.

In 2007, the FDA finally approved the first stand-alone human thrombin preparation, Evithrom ${ }^{\circledR}$ (OMRIX Biopharmaceuticals Ltd, New York, New York, USA). ${ }^{35}$ (US Food and Drug Administration 2007). Previously, human thrombin was only used in FDA-approved combination products, namely Floseal ${ }^{\circledR}$ (Baxter; Deerfield, IL, USA), and the fibrin glues (to be discussed in greater detail later).

Results from a published clinical trial of Evithrom versus bovine thrombin can be found in the packet insert for Evithrom. In this phase III, prospective, randomized, controlled, double-blinded study of 305 subjects at 22 centers in the US, subjects undergoing elective cardiovascular, neurological (spinal) or general surgical procedures were randomized to treat oozing or bleeding (of mild intensity that could not be controlled by other surgical techniques) with bovine thrombin and Surgifoam ${ }^{\circledR}$ (Johnson and Johnson Wound Management, Somerville, NJ, USA); or Evithrom and Surgifoam. Treatment with Evithrom was as successful as treatment with bovine thrombin in achieving the primary efficacy endpoint: hemostasis within 10 minutes of product application. The secondary efficacy endpoint of hemostasis within 6 and 3 minutes of product application also was achieved. In terms of safety, there was no difference between the two groups.

Nearly all patients experienced one or more adverse events $(99.7 \%)$, with the majority being laboratory abnormalities in both groups. In the Evithrom group 17\% had serious adverse events as compared to $11 \%$ in the bovine thrombin group. Two subjects (1.3\%) in the Evithrom group experienced a severe adverse event: respiratory arrest and post-procedural hematoma in one subject and an extradural hematoma in the other. Two (1.3\%) subjects in the bovine thrombin group experienced severe adverse events: pyrexia and post-procedural hematoma. Twelve percent who experienced one or more adverse events were considered possibly, probably, or definitely related to the study drugs. No deaths were reported during the study period. ${ }^{36}$ Limitations of the study which, to the author's credit, are detailed in the article, include the lack of a placebo-control group, the potential for intersurgeon variability, and the fact that antibody assessment was not evaluable in all patients.

\section{Recombinant human thrombin (rThrombin)}

The development of a recombinant human thrombin, Recothrom ${ }^{\circledR}$ (Zymogenetics, Inc, Seattle, Washington, USA), provides a manufactured source of thrombin that is devoid of the risks of antibody development found with bovine thrombin or the theoretic risks of viral transmission with human-derived thrombin. Recombinant thrombin has the identical amino acid sequence to human thrombin, and its precursors are made from a genetically-modified Chinese hamster ovary cell line. Enzymes derived from snake venom are used to activate the precursors to human thrombin. Although, hypothetically, Recothrom is free from infectious agents, there is still a final purification process with solventdetergent treatment and nanofiltration. This product has been approved by the US FDA since January 2008. ${ }^{3,4}$

Preclinical studies demonstrated rThrombin to be safe in animal subjects. ${ }^{33}$ Phase 2 trials have been completed comparing the safety profile of rThrombin to placebo. One hundred and thirty patients undergoing AV graft, liver resections, peripheral artery bypass, or spinal surgery were randomized to either rThrombin or placebo soaked in Gelfoam ${ }^{\circledR}$ (Pharmacia \& Upjohn, Bridgewater, NJ, USA) or Surgifoam. No patterns of treatment-related adverse events were associated with rThrombin. Recombinant thrombin induced minimal antibody generation and no antibody-mediated reactions to coagulation proteins were documented. ${ }^{37}$

A phase 3 trial compared the efficacy, safety, and antigenicity of rThrombin versus bovine thrombin. Four hundred and one patients undergoing liver resection, spine, peripheral arterial bypass, or dialysis access surgery were randomly assigned to either rThrombin or bovine thrombin (bThrombin) for surgical hemostasis. A gelatin sponge was used as a carrier. Hemostasis was achieved at the time-tohemostasis evaluation site within 10 minutes in $95 \%$ of patients in each treatment group. Overall complications, including operative mortality, adverse events, and laboratory abnormalities, were similar between groups. However, in terms of antigenicity, $21.5 \%$ of the patients receiving bovine thrombin developed antibodies to the product whereas only $1.5 \%$ in the rThrombin group developed antibodies to rThrombin, $P<0.0001$.

In post hoc analysis, those that developed anti-bThrombin antibodies $(n=43)$ had a numerically higher incidence of 
bleeding, thromboembolic events, hypersensitivity, and abnormal activated partial thromboplastin time (aPTT) as compared to those in the bThrombin group that did not develop antibodies $(n=157)$. This increase was not seen in those with anti-rThrombin antibodies $(n=3)$ as compared to those in the rThrombin group that did not develop antibodies $(\mathrm{n}=198) .{ }^{38}$

The companion study for the vascular subgroup in the previously mentioned phase 3 trial showed that adverse events were similar between the two thrombins in this subgroup. In patients undergoing vascular surgery, rThrombin demonstrated a superior immunogenicity profile versus bThrombin. Moreover, a significantly greater proportion of patients receiving rThrombin achieved hemostasis at 3 minutes compared with bThrombin (55\% versus $39 \%$, $P<0.05){ }^{39}$

Pooled results from a recently-published analysis from 8 clinical trials further show compelling evidence of the safety and the low immunogenicity of rThrombin. Data from 8 clinical trials, including the three mentioned above, were used to evaluate the safety and immunogenicity observations of rThrombin. Collectively, these trials included patients undergoing spinal procedures, major hepatic resections, creation of arterivenous grafts for hemodialysis access, peripheral arterial bypass procedures, and skin grafting for burn wounds. Adverse events and laboratory parameters were monitored until 29 days after the procedures. Immunogenicity was evaluated on plasma samples collected at baseline and on day 29. Of the 583 patients who were treated with rThrombin, $5(0.9 \%)$ patients developed antibodies to rThrombin 29 days after surgery, and these antibodies did not neutralize the biologic activity of native human thrombin (immunologic data only available for 552 patients). Adverse events reported for $\geq 10 \%$ of patients included incisional site pain, procedural pain, nausea, constipation, pyrexia, anemia, insomnia, vomiting, and pruritis. The reported adverse events were generally consistent with postprocedural events that are usually reported for patients undergoing surgery. Twelve $(2.2 \%)$ patients with no previous exposure to rThrombin had pre-existing antibodies to rThrombin, however their antibody titers did not increase $\geq 10$-fold at day 29. The collective results from this analysis demonstrate that rThrombin is well tolerated as a topical hemostatic agent in many surgical settings, and the data further contributes to the evidence of its safety and low immunogenic reactivity. ${ }^{40}$

Similar safety and immunogenic reactivity data seen in the above surgical patients were also seen in patients undergoing skin grafting for burns. This phase 2, multicenter, open-label study was of 72 patients with burn wounds who underwent partial or full-thickness autologous skin grafting. Patients received a spray application of rThrombin once every 5 minutes for up to 20 minutes. Of 62 patients for whom data was available, 1 patient (1.6\%) developed anti-rThrombin antibodies at day 29. One other patient had pre-existing antibodies to rThrombin, however neither of these antibodies to rThrombin neutralized native human thrombin. Adverse events occurred in the majority of patients, however all were typical sequelae of skin grafting. ${ }^{41}$

One safety issue that has been raised is the question of whether rThrombin would be safe to use in patients who have received other forms of thrombin, such as bovine thrombin, in the past. There is a suggestion that the antibodies formed in those with prior exposure to bovine thrombin may cross-react with $r$ Thrombin. ${ }^{42}$ A recent phase $3 \mathrm{~b}$, open-label, single-group study addressed this issue by evaluating the immunogenicity and safety of rThrombin in 209 vascular and spinal operation patients at high risk for pre-existing anti-bovine thrombin antibodies, who received rThrombin as a topical hemostat. Immunogenicity data were collected at baseline and approximately 1 month after the operation. Of the 200 patients with complete immunogenicity data, $31(15.5 \%)$ had pre-existing anti-bovine thrombin antibodies, and $4(2 \%)$ had pre-existing anti-rThrombin antibodies. None of the 200 patients developed new antibodies against rThrombin on day 29 (defined as $\geq 10$-fold increase in titer). The reported adverse events were generally as expected for a surgical population and seemed similar for patients with or without pre-existing anti-bovine thrombin antibodies. The results of this study shed light on the issue of the potential cross-reactivity of pre-existing antibovine antibodies with patients treated with rThrombin. It provides evidence that the use of topical rThrombin is well tolerated in patients with or without pre-existing antibodies to bovine thrombin, and is safe in these patients undergoing vascular or spinal operations. ${ }^{43}$

\section{Mechanisms of delivery}

Thrombin is used predominantly as a topical agent for bleeding that cannot be controlled with suture ligation or electrocautery. It is particularly useful in neurosurgical applications near the spine, in liver surgery where there is raw liver surface bleeding, and in vascular surgery where needle holes in polytetrafluoroethylene (PTFE) grafts continue to ooze.

There are many ways thrombin is used during a surgical procedure to effect hemostasis. It can be used alone, in combination with an absorbable hemostatic carrier, or in a 
manufactured combination with fibrin. Given the previous discussion, it is important to know the source of thrombin (bovine, human, recombinant), and the source of any other additives in the manufactured preparations.

\section{Thrombin used alone}

In the past pure thrombin was only available from a bovine source, and manufactured as thrombin-JMI ${ }^{\circledR}$ (King Pharmaceuticals, Inc, Bristol, TN, USA). Now there is also human thrombin (Evithrom) and recently, a recombinant thrombin (Recothrom).

Thrombin-JMI and Recothrom are stored at room temperature, as a powder, which is reconstituted with saline into solution for use. ${ }^{44,45}$ Evithrom is packaged as a solution, and stored in a freezer. Otherwise it can be refrigerated for up to 30 days, or kept at room temperature for up to 24 hours. ${ }^{34}$ All stand alone thrombins, regardless of origin, are applied as a solution and can be cumbersome for topical application unless sprayed into a mist, or used with another carrier (like the absorbable hemostatic agents) or in combination with fibrinogen to create a 'glue'.

\section{Thrombin combined with an inert carrier}

Gelatin sponges are absorbable hemostatic agents that can be used alone or in combination with thrombin. Surgical use of gelatin sponges were first introduced in the 1940s for neurosurgical procedures. The gelatin consists of a purified pork or bovine skin. Its surface causes activation of the intrinsic coagulation pathway but its main effect is its ability to absorb approximately 45 times its weight, expanding to approximately $200 \%$ of its initial volume (Figure $1(*)$ ). This facilitates a concentration of coagulation factors at the site of bleeding. A number of manufactured versions exist, and it is available as a sheet, powder, prepackaged in a syringe, or even prepackaged with thrombin.

Gelfoam $^{\circledR}$ (Pharmacia \& Upjohn, Bridgewater, NJ, USA) comes in sheets, Surgifoam is also a sheet or powder, and Surgiflo ${ }^{\circledR}$ (Johnson and Johnson Wound Management, Somerville, NJ, USA) is available in an applicator syringe that allows for the addition of any thrombin solution. All these products carry a theoretic risk for antigenicity given they are derived from nonhuman sources, but to date no adverse events have been linked to gelatin formulations.

One issue with these agents is that their porous nature can cause expansion. In closed spaces like the spinal canal, cases have been reported where this expansion led to spinal cord compression injuries. ${ }^{46}$ In addition, there is also the possible risk of embolization if applied to open arterial bleeding rather than diffuse oozing. However, these risks are low and the user-friendly nature of the absorbable hemostatic agents makes them popular surgical ancillaries which are widely and frequently used by most surgical specialties.

Floseal is a prepackaged gelatin matrix with a separate human thrombin component. This human thrombin is a powder that is reconstituted with a calcium chloride solution then mixed with the gelatin matrix in a delivery syringe. Initially, both the gelatin and thrombin were from bovine origin, but in 2002 Baxter replaced the bovine thrombin with pooled human plasma thrombin. The gelatin matrix contains microgranules cross-linked with glutaraldehyde and human thrombin. Its action requires blood as the source of fibrinogen, on which contact, the gelatin granules expand to produce a tamponade-effect. ${ }^{47}$

\section{Thrombin and fibrinogen (fibrin glue)}

Fibrin glues contain thrombin and fibrinogen. When combined the fibrinogen is activated by thrombin and converted into fibrin monomers. This forms an adhesive glue at the tissues applied. The fibrin monomers go on to interact with the patient's own factor XIII and calcium to convert the final product into a fibrin polymer that allows for platelet activation and aggregation with subsequent hemostasis (Figure 1).

Fibrin glues come packaged with a dual chamber syringe that allows for the combination of the thrombin and fibrinogen after the plunger is depressed. Commercially available products include Tisseel ${ }^{\circledR}$ (Baxter; Deerfield, IL, US) and Evicel $^{\circledR}$ (Johnson and Johnson Wound Management). All components in Evicel (formerly Crosseal ${ }^{\circledR}$ ) are human derived. Tisseel uses thrombin and fibrinogen derived from human sources, but there is an additional fibrinolysis inhibitor added to the fibrinogen component to prevent premature fibrinolysis after the fibrin glue is applied. This fibrinolysis inhibitor was originally extracted from bovine source material, but in 2007 this was replaced with a synthetic inhibitor, rendering Tisseel bovine free. ${ }^{32}$

\section{Indications for use}

All the above combination products are effective and none has demonstrated singular superiority with the exception of a few specific surgical settings. Currently, bovine thrombin is the most common thrombin used alone or in combination with a gelatin sponge. Manufactured combination products such as the fibrin glues and Floseal contain almost exclusively human thrombin. Recombinant thrombin which was just recently approved may replace bovine or human thrombin 
in many of these applications, but to what degree remains to be seen.

For any given surgical procedure, it is mainly dependent on surgeon preference which thrombin or combination product is used. In general, the stand-alone thrombin spray is used to assist in hemostasis of large, raw surface areas such as in the case of solid viscera injury and resection of retroperitoneal tumors. Gelatin/thrombin combinations are very helpful in achieving hemostasis in vascular and spinal procedures and the fibrin glues are most commonly used in reoperative cardiac procedures which are complicated by persistent and difficult to control mediastinal bleeding. The effectiveness of the gelatin/ thrombin combination to achieve hemostasis has been extensively studied and they have been found to be quite effective. The different fibrin glues have also been studied in numerous surgical settings including liver resections, ${ }^{48}$ vascular PTFE grafts, ${ }^{49,50}$ and even inguinal hernia repairs. ${ }^{51}$

\section{Conclusion}

Thrombin has had a long history in surgical hemostasis, and has proven to be a useful and effective ancillary for surgical hemostasis. Early bovine thrombin formulations have been conclusively linked to the development of antibodies that cross-react with multiple human coagulation proteins, factor $\mathrm{V}$ being the most important. These bovine-induced antibodies to human coagulation factors have led to numerous cases of life threatening bleeding and other complications. The development of human thrombin has provided an alternative to bovine thrombin, but it has the theoretic risk of viral transmission. The recent development and FDA approval of a recombinant protein thrombin product provides yet another potential alternative, with equal efficacy to bovine thrombin, without the attendant risk of antigenicity. ${ }^{38}$

\section{Disclosure}

Fred Weaver, MD has served as a consultant for Zymogenetics and has received research grant support from Zymogenetics.

\section{References}

1. Brister SJ, Ofosu FA, Buchanan MR. Thrombin: its key role in thrombogenesis: implications for its inhibition clinically. Boca Raton, FL: CRC Press, 1994.

2. Lawson JH. The clinical use and immunologic impact of thrombin in surgery. Semin Thromb Hemost. 2006 Apr;32 Suppl 1:98-110.

3. FDA-RECOTHROM Product Approval Information. Available at: http://www.fda.gov/BiologicsBloodVaccines/BloodBloodProducts/ ApprovedProducts/LicensedProductsBLAs/FractionatedPlasmaProducts/ucm089451.htm. Accessed Apr 29, 2010.

4. US Food and Drug Administration. FDA News. Jan 17, 2008. Available at: http://www.fda.gov/NewsEvents/Newsroom/PressAnnouncements/2008/ ucm116838.htm. Accessed Apr 28, 2010.
5. Patterson C, Stouffer GA, Madamanchi N, Runge MS. New tricks for old dogs: nonthrombotic effects of thrombin in vessel wall biology. Circ Res. 2001;88(10):987-997.

6. Dahlback B. Blood coagulation. Lancet. 2000;355(9215):1627-1632.

7. Flaherty MJ, Henderson R, Wener MH. Iatrogenic immunization with bovine thrombin: a mechanism for prolonged thrombin times after surgery. Ann Intern Med. 1989;111(8):631-634.

8. Zehnder JL, Leung LL. Development of antibodies to thrombin and factor $\mathrm{V}$ with recurrent bleeding in a patient exposed to topical bovine thrombin. Blood. 1990;76(10):2011-2016.

9. Lawson JH, Pennell BJ, Olson JD, Mann KG. Isolation and characterization of an acquired antithrombin antibody. Blood. 1990;76(11):2249-2257.

10. Rapaport SI, Zivelin A, Minow RA, Hunter CS, Donnelly K. Clinical significance of antibodies to bovine and human thrombin and factor V after surgical use of bovine thrombin. Am J Clin Pathol. 1992;97(1):84-91.

11. Ortel TL, Charles LA, Keller FG, et al. Topical thrombin and acquired coagulation factor inhibitors: clinical spectrum and laboratory diagnosis. Am J Hematol. 1994;45(2):128-135.

12. Sands JJ, Nudo SA, Ashford RG, Moore KD, Ortel TL. Antibodies to topical bovine thrombin correlate with access thrombosis. Am J Kidney Dis. 2000;35(5):796-801.

13. Fastenau DR, Hormuth DA, McIntyre JA. Antiphospholipid antibodies in left-ventricular assist system recipients after exposure to topical bovine thrombin. Transplant Proc. 1999;31(1-2):141-142.

14. Schoenecker JG, Johnson RK, Lesher AP, et al. Exposure of mice to topical bovine thrombin induces systemic autoimmunity. Am J Pathol. 2001;159(5):1957-1969.

15. Ortel TL, Mercer MC, Thames EH, Moore KD, Lawson JH. Immunologic impact and clinical outcomes after surgical exposure to bovine thrombin. Ann Surg. 2001;233(1):88-96.

16. Streiff MB, Ness PM. Acquired FV inhibitors: a needless iatrogenic complication of bovine thrombin exposure. Transfusion. 2002;42(1):18-26.

17. Spero JA. Bovine thrombin-induced inhibitor of factor $\mathrm{V}$ and bleeding risk in postoperative neurosurgical patients. Report of three cases. J Neurosurg. 1993;78(5):817-820.

18. Banninger H, Hardegger T, Tobler A, et al. Fibrin glue in surgery: frequent development of inhibitors of bovine thrombin and human factor V. Br J Haematol. 1993;85(3):528-532.

19. Poynton AR, Nelson MC, McCance SE, Levine RL, O’Leary PF. Bovine thrombin induces an acquired coagulopathy in sensitized patients undergoing revision spinal surgery: a report of two cases. Spine (Phila Pa 1976). 2003;28(12):E221-E223.

20. Muntean W, Zenz W, Finding K, Zobel G, Beitzke A. Inhibitor to factor $\mathrm{V}$ after exposure to fibrin sealant during cardiac surgery in a two-year-old child. Acta Paediatr. 1994;83(1):84-87.

21. Israels SJ, Israels ED. Development of antibodies to bovine and human factor $\mathrm{V}$ in two children after exposure to topical bovine thrombin. Am J Pediatr Hematol Oncol. 1994;16(3):249-254.

22. Israels SJ, Leaker MT. Acquired inhibitors to factors $V$ and $X$ after exposure to topical thrombin: interference with monitoring of low molecular weight heparin and warfarin. J Pediatr. 1997 Sep;131(3):480-483.

23. Savage WJ, Kickler TS, Takemoto CM. Acquired coagulation factor inhibitors in children after topical bovine thrombin exposure. Pediatr Blood Cancer. 2007;49(7):1025-1029.

24. Berruyer M, Amiral J, Ffrench P, et al. Immunization by bovine thrombin used with fibrin glue during cardiovascular operations. Development of thrombin and factor V inhibitors. J Thorac Cardiovasc Surg. 1993;105(5):892-897.

25. Lawson JH, Lynn KA, Vanmatre RM, et al. Antihuman factor V antibodies after use of relatively pure bovine thrombin. Ann Thorac Surg. 2005;79(3):1037-1038.

26. Adams JD, Jones S, Brost BC. Development of antibodies to topical bovine thrombin after abdominal hysterectomy. A case report. $J$ Reprod Med. 2001;46(10):909-912. 
27. Kajitani M, Ozdemir A, Aguinaga M, Jazieh AR, Flick JT, Antakli T. Severe hemorrhagic complication due to acquired factor $\mathrm{V}$ inhibitor after single exposure to bovine thrombin product. J Card Surg. 2000;15(6):378-382.

28. Sarfati MR, Dilorenzo DJ, Kraiss LW, Galt SW. Severe coagulopathy following intraoperative use of topical thrombin. Ann Vasc Surg. 2004;18(3):349-351.

29. Pavlovich CP, Battiwalla M, Rick ME, Walther MM. Antibody induced coagulopathy from bovine thrombin use during partial nephrectomy. J Urol. 2001;165(5):1617.

30. Timmerman L. Bloomberg News. FDA allows ZymoGenetics to skip trial of spray drug, saving time and money. Mar 7, 2007, Available at http://seattletimes.nwsource.com/html/biotech/2003605976_ webzymo07.html

31. Jackson MR. Fibrin sealants in surgical practice: An overview. $A m$ J Surg. 2001;182 Suppl 2:1S-7S.

32. Baxter. Prescribing information: Tisseel, 2010. Available at: http:// www.baxter.com/healthcare_professionals/products/tisseel.html

33. Heffernan JK, Ponce RA, Zuckerman LA, et al. Preclinical safety of recombinant human thrombin. Regul Toxicol Pharmacol. 2007;47(1): $48-58$.

34. OMRIX Biopharmaceuticals Ltd. Ethicon, Inc. (J\&J Wound Management) Prescribing information: Evithrom, 2007. Available at: http:// www.ethicon360.com/sites/default/files/products/Appendix $\% 20$ 1A\%20Evithrom_Leaflet_July\%202009.pdf

35. US Food and Drug Administration. FDA Approves Human Thrombin for Topical Use in Surgery FDA News. Aug 28, 2007. Available at: http:// www.fda.gov/NewsEvents/Newsroom/PressAnnouncements/2007/ ucm108973.htm. Accessed Apr 28, 2010.

36. Doria C, Fischer CP, Wood CG, et al. Phase 3, randomized, doubleblind study of plasma-derived human thrombin versus bovine thrombin in achieving hemostasis in patients undergoing surgery. Curr Med Res Opin. 2008;24(3):785-794.

37. Chapman WC, Lockstadt H, Singla N, Kafie FE, Lawson JH. Phase 2, randomized, double-blind, placebo-controlled, multicenter clinical evaluation of recombinant human thrombin in multiple surgical indications. J Thromb Haemost. 2006;4(9):2083-2085.

38. Chapman WC, Singla N, Genyk Y, et al. A phase 3, randomized, doubleblind comparative study of the efficacy and safety of topical recombinant human thrombin and bovine thrombin in surgical hemostasis. J Am Coll Surg. 2007;205(2):256-265.
39. Weaver FA, Lew W, Granke K, Yonehiro L, Delange B, Alexander WA. A comparison of recombinant thrombin to bovine thrombin as a hemostatic ancillary in patients undergoing peripheral arterial bypass and arteriovenous graft procedures. JVasc Surg. 2008;47(6):1266-1273.

40. Ballard JL, Weaver FA, Singla NK, Chapman WC, Alexander WA. Safety and immunogenicity observations pooled from eight clinical trials of recombinant human thrombin. J Am Coll Surg. 2010;210(2): 199-204.

41. Greenhalgh DG, Gamelli RL, Collins J, et al. Recombinant thrombin: safety and immunogenicity in burn wound excision and grafting. J Burn Care Res. 2009;30(3):371-379.

42. Zhu H, Hoppensteadt D, Adiguzal C, Jeske W, Messmore H, Fareed J. Cross Reactivity of Human Recombinant thrombin (Recothrombin) to Antibovine Thrombin Antibodies. Clinical Implications. FASEB J. Apr 1, 2009;23(1 MeetingAbstracts):569.511.

43. Singla NK, Ballard JL, Moneta G, Randleman CD Jr, Renkens KL, Alexander WA. A phase 3b, open-label, single-group immunogenicity and safety study of topical recombinant thrombin in surgical hemostasis. J Am Coll Surg. 2009;209(1):68-74.

44. ZymoGenetics, Inc. Prescribing information: RECOTHROM, 2009. Accessed.

45. King Pharmaceuticals Inc. Prescribing information: Thrombin-JMI, 2007.

46. Sabel M, Stummer W. The use of local agents: Surgicel and Surgifoam. Eur Spine J. 2004;13 Suppl 1:S97-S101.

47. Baxter. Prescribing information: Floseal, 2005.

48. Schwartz M, Madariaga J, Hirose R, et al. Comparison of a new fibrin sealant with standard topical hemostatic agents. Arch Surg. 2004;139(11):1148-1154

49. Glickman M, Gheissari A, Money S, Martin J, Ballard JL. A polymeric sealant inhibits anastomotic suture hole bleeding more rapidly than gelfoam/thrombin: results of a randomized controlled trial. Arch Surg. 2002;137(3):326-331; discussion 332.

50. Taylor LM Jr, Mueller-Velten G, Koslow A, Hunter G, Naslund T, Kline R. Prospective randomized multicenter trial of fibrin sealant versus thrombin-soaked gelatin sponge for suture- or needle-hole bleeding from polytetrafluoroethylene femoral artery grafts. J Vasc Surg. 2003;38(4):766-771.

51. Canonico $\mathrm{S}$. The use of human fibrin glue in the surgical operations. Acta Biomed. 2003;74 Suppl 2:21-25.
Journal of Blood Medicine

\section{Publish your work in this journal}

The Journal of Blood Medicine is an international, peer-reviewed, open access, online journal publishing laboratory, experimental and clinical aspects of all topics pertaining to blood based medicine including but not limited to: Transfusion Medicine; Blood collection, Donor issues, Transmittable diseases, and Blood banking logistics; Immunohematology; Artificial and alternative

\section{Dovepress}

blood based therapeutics; Hematology; Biotechnology/nanotechnology of blood related medicine; Legal aspects of blood medicine; Historical perspectives. The manuscript management system is completely online and includes a very quick and fair peer-review system. Visit http://www.dovepress.com/ testimonials.php to read real quotes from published authors. 